\title{
Management of Delayed Reimplanted Avulsed Young Permanent Tooth by Decoronation: A Case Report
}

\author{
Bindu Kadian ${ }^{1}$, Natasha Saini ${ }^{2}$, Saumil Mogre ${ }^{3}$, Tanu Rajain $^{4}$, Ritu Namdev ${ }^{5}$
}

\begin{abstract}
Avulsed teeth with extraoral dry time for $>60$ minutes generally undergo replacement root resorption or ankylosis after their replantation. The complications that may arise due to ankylosis are tooth infrapositioning and the local arrest of alveolar bone growth. Removal of an ankylosed tooth is traumatic and may cause bony ridge deformities that interfere with optimal prosthetic treatment. Therefore, the "decoronation" technique gained interest, to remove an ankylosed tooth in such a way that the alveolar ridge is preserved. This article describes a case of a delayed reimplanted avulsed tooth that was managed with decoronation technique.

Keywords: Ankylosis, Avulsion, Decoronation, Replacement root resorption.

Journal of South Asian Association of Pediatric Dentistry (2021): 10.5005/jp-journals-10077-3063
\end{abstract}

\section{INTRODUCTION}

Maximum traumatic dental injuries in permanent teeth are reported to occur between 8 years and 10 years of age. ${ }^{1}$ Avulsion is considered one of the severe types of trauma and its incidence varies between $1 \%$ and $16 \% .^{2}$ The presence of a high metallic percussion sound and immobility of the tooth indicates ankylosis and a negative prognosis for the young permanent tooth. ${ }^{3}$ The absence of apexogenesis and root resorption are the radiographic findings. ${ }^{3}$ Time constitutes one of the significant factors for the management of the avulsed tooth. As immediate reimplantation of an avulsed tooth is an optimal protocol for the management. Use of storage media like milk, Hank's Balanced Salt Solution (HBSS) is encouraged to over dry storage of the avulsed tooth. Storing the tooth in inappropriate storage media due to lack of awareness before reimplantation can result in loss of vitality of periodontal ligament (PDL) cells covering the root surface of the tooth due to excessive drying. This can result in ankylosis and replacement root resorption. ${ }^{4}$ In $51 \%{ }^{3}$ of the avulsed tooth cases after 12 weeks of injury, replacement root resorption is detected. ${ }^{5}$ Infraocclusion occurs after ankylosis of the tooth if not treated will result in space loss due to tilting of adjacent teeth and also alveolar bone growth is arrested. ${ }^{6}$

The accepted treatment for the infrapositioned ankylosed tooth was extraction until 1984. To conserve the surrounding alveolar bone, the process of decoronation was suggested by Malmgren et al. ${ }^{7}$ for this complication. The decoronation technique involves the removal of crown and root filling material and providing the resorbing root as a matrix for new bone formation. ${ }^{8}$ The following clinical guidelines may be applied for the diagnosed ankylosis cases-decoronation within 2 years in early mixed dentition (7-10 years). Individual monitoring is required in the late mixed dentition (10-12 years). An increase in infraocclusion cases is seen if pubertal growth spurt has been reached. Decoronation might not be needed and only annual follow-up will be required in the case of early permanent dentition. ${ }^{6}$ In replacement resorption cases, decoronation can be considered as a treatment of choice as the lost vertical bone is rebuilt and the vestibular-palatal width of alveolar bone is preserved for years. ${ }^{3}$

The following case report describes a case of a delayed reimplanted avulsed and ankylosed tooth that was treated by
${ }^{1-5}$ Department of Pedodontics and Preventive Dentistry, Postgraduate Institute of Dental Sciences, Rohtak, Haryana, India

Corresponding Author: Bindu Kadian, Department of Pedodontics and Preventive Dentistry, Postgraduate Institute of Dental Sciences, Rohtak, Haryana, India, Phone: +91 9466349024, e-mail: Bindu.18july@ gmail.com

How to cite this article: Kadian B, Saini N, Mogre S, et al. Management of Delayed Reimplanted Avulsed Young Permanent Tooth by Decoronation: A Case Report. J South Asian Assoc Pediatr Dent 2021;4(1):50-53.

Source of support: Nil

Conflict of interest: None

decoronation. The preservation of width and vertical height of the alveolar ridge was noted in the follow-up period.

\section{Case Description}

An 8-year-old female patient presented with a complaint of avulsed maxillary right central incisor due to a fall from a bicycle. The patient reported with the avulsed tooth in cotton which had an extraoral dry time of 120 minutes. Medical and dental history was taken, which was unremarkable. On clinical examination, an avulsion of 11 was present with slight mobility in 21 and abrasion of the upper lip (Fig. 1). In accordance with International Association of Dental Traumatology (IADT) protocol, the informed consent was taken and the tooth root surface was treated with $2 \% \mathrm{NaF}$ solution for 20 minutes. An avulsed tooth was young permanent, corresponding to Nolla's stage 9 of tooth development.

Under local anesthesia, the tooth was reimplanted into the socket with slight digital pressure. The position of the reimplanted tooth was verified clinically and radiographically. Then, it was splinted with a flexible wire-composite splint for 4 weeks (Fig. 2). Before discharging as per IADT guidelines, tetanus protection, systemic antibiotics, and postoperative instructions were provided.

The patient was recalled after 10 days for endodontic procedure, apexification. After pulp extirpation, the canal was filled with radio-opaque non-setting calcium hydroxide paste to form an

(c) The Author(s). 2021 Open Access This article is distributed under the terms of the Creative Commons Attribution 4.0 International License (https:// creativecommons.org/licenses/by-nc/4.0/), which permits unrestricted use, distribution, and non-commercial reproduction in any medium, provided you give appropriate credit to the original author(s) and the source, provide a link to the Creative Commons license, and indicate if changes were made. The Creative Commons Public Domain Dedication waiver (http://creativecommons.org/publicdomain/zero/1.0/) applies to the data made available in this article, unless otherwise stated. 


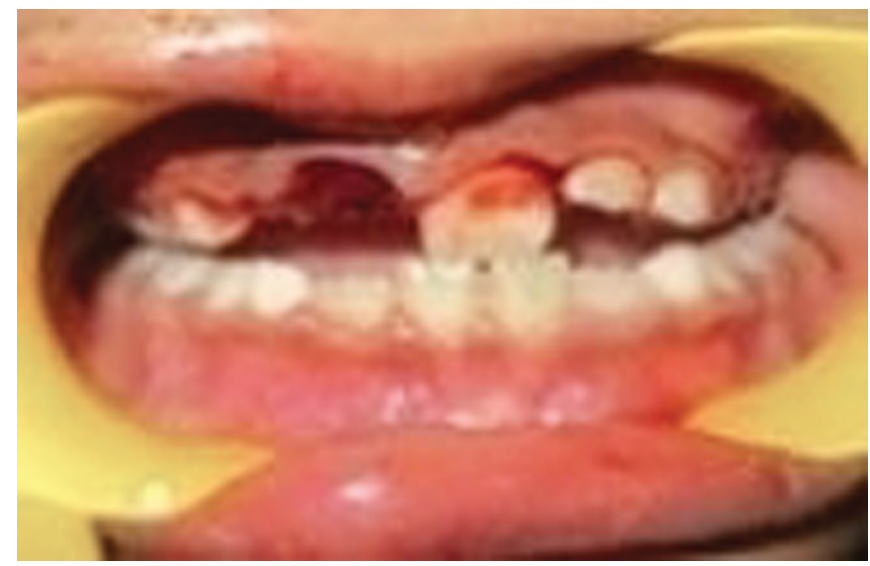

Fig. 1: Preoperative clinical view after trauma

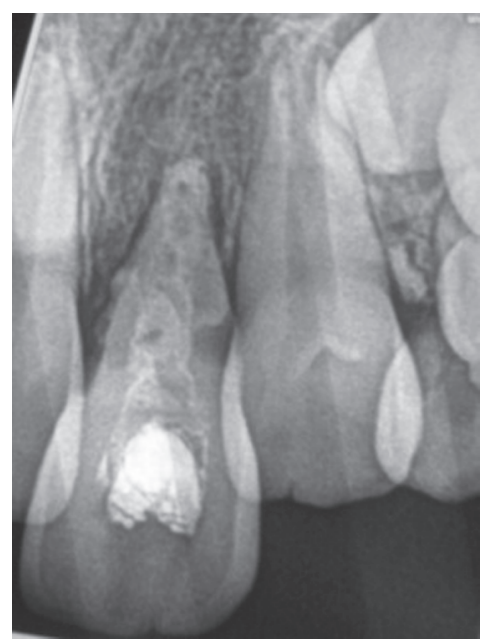

Fig. 3: Radiographic examination of the right maxillary central incisor with inflammatory root resorption (bowl-shaped) 3 months after replantation

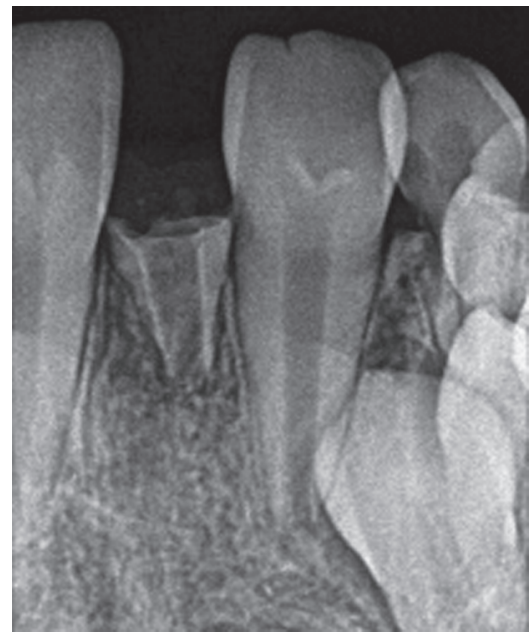

Fig. 5: Radiograph after decoronation

apical barrier and prevent the root resorption. After 4 weeks, the splint was removed.

Radiographic evaluation of the reimplanted tooth after 1 month showed crater-shaped resorption area on the external surface of the root (Fig. 3). The dressing was changed and the patient was

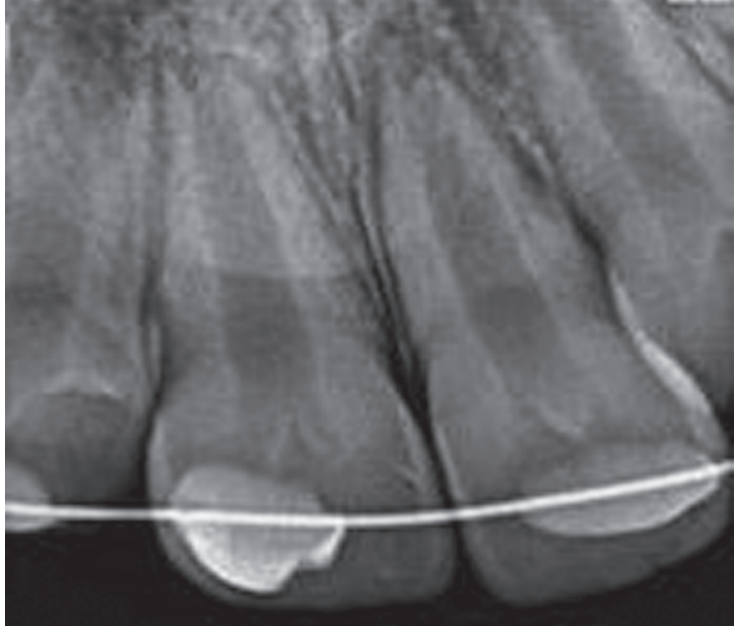

Fig. 2: Postreplantation radiograph. 11 with immature root formation

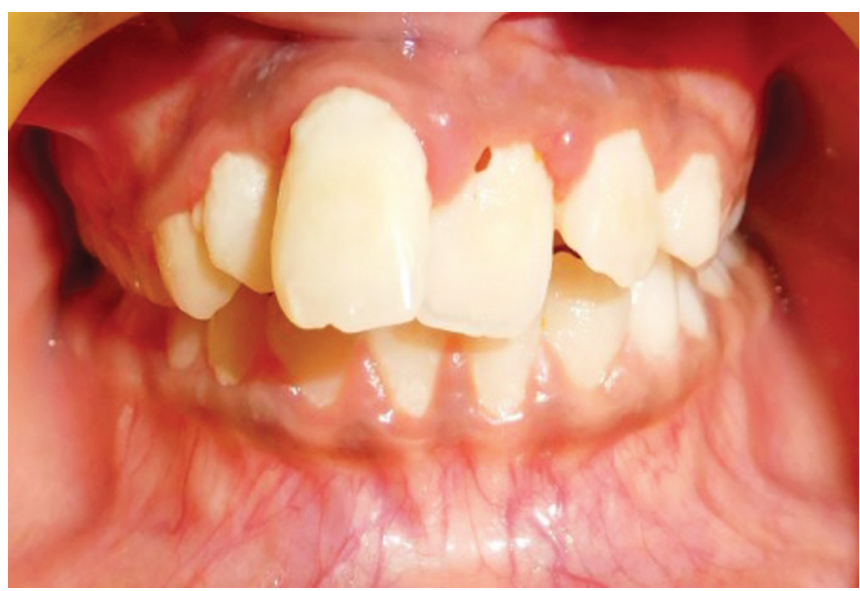

Fig. 4: Clinical photograph of buccally positioned right maxillary and mesially tilted left maxillary central incisor

again monitored at the one-month interval. But the condition did not improve and resulted in ankylosis and resorption of the tooth. After 6 months, the reimplanted tooth came out of the arch and started impinging the lower lip and the adjacent teeth tipped mesially which, resulted in space loss (Fig. 4). So, to maintain the arch integrity and alveolar bone width decoronation of maxillary right central incisor was planned and explained to the parents.

After taking informed consent, the decoronation technique was initiated with the raising of a mucoperiosteal flap to gain direct access to the ankylosed tooth under local anesthesia. Then, by using a diamond bur under continuous saline irrigation, odontosection of the crown was performed $2 \mathrm{~mm}$ below the marginal bone (Fig. 5). After it, by using the $\mathrm{K}$ file filling from the canal was removed and the empty root canal was rinsed with saline solution, allowing the rinsed canal to fill with blood (Fig. 6). The mucoperiosteal flap was repositioned over the alveolus and sutured. The removed crown was preserved in saline for future use as a natural toot pontic.

Two weeks later, orthodontic treatment was initiated to regain the space lost due to mesial tipping of the teeth adjacent to the decoronated tooth. After regaining the space, a natural tooth pontic was provided which was fixed to the adjacent teeth with a ribbond (Fig. 7). Afterward, it was replaced by a fixed functional appliance having a lingual archwire soldered to the band on the first permanent molars, with a denture tooth fixed to the archwire 


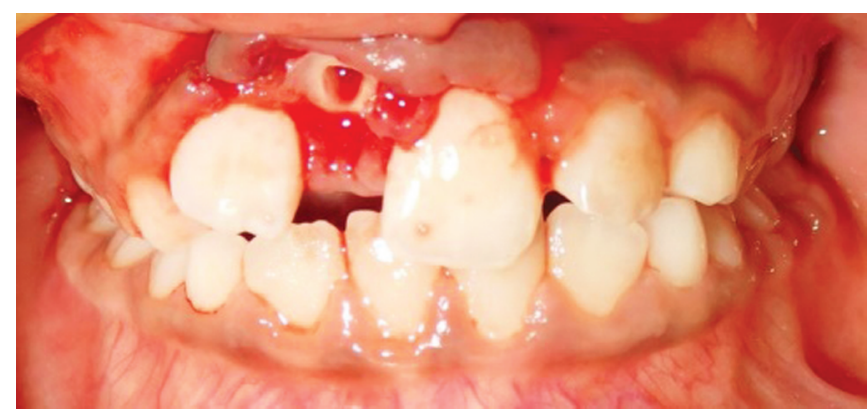

Fig. 6: Frontal view after decoronation, canal of right maxillary central incisor filled with blood

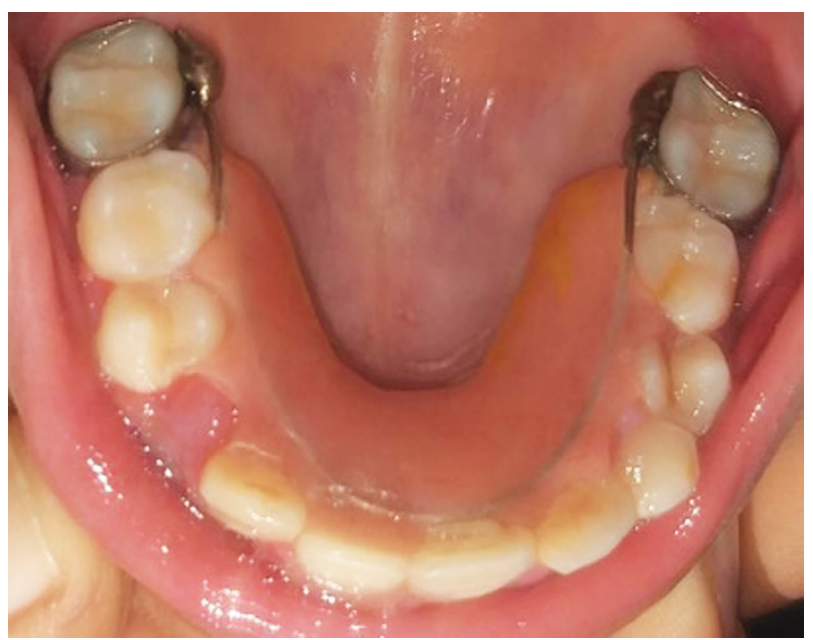

Fig. 8: Palatal view of fixed functional appliance

(Fig. 8). The clearance was provided between the pontic tooth and the sectioned root to accommodate the growing coronal bone. The patient was regularly recalled for clinical and radiographic examination at 6 months intervals for 4 years (Fig. 9).

\section{Discussion}

An avulsion is a complete displacement of the tooth from its sockets that is associated with extensive damage to the pulp and the periodontal tissues. Andreasen and Vestergaard Pedersen reported that the age of the patient, stage of root formation, tooth type, potential crown fracture, and extent of displacement are some of the factors associated with injury and can influence the healing prognosis. ${ }^{3,9}$ Among the four possible sequelae associated with healing of damaged PDL, replacement root resorption or ankylosis is one of them. The histological findings seen are a fusion of dentin with the surrounding bone with resorption pits where the dentin, the PDL, and the cementum have been resorbed actively by the multinucleated osteoclast. It is seen radiographically that the PDL space is completely lost and it appears to merge with the surrounding bone. ${ }^{10}$ Judicious management of an ankylosed tooth is seen in an adult patient, whereas it is challenging in growing children due to excessive rate of replacement root resorption. ${ }^{6}$

Ankylosed tooth extraction is not advisable in young patients as the procedure is traumatic for them and also there is an increased risk of alveolar bone loss mainly in the buccolingual or palatal dimension. ${ }^{11}$ Decoronation procedure is performed in infraocclusion cases, i.e., if during the growth spurt ankylosis occurs. In such cases, the clinical and radiographic monitoring of the root resorption and bone formation is important.

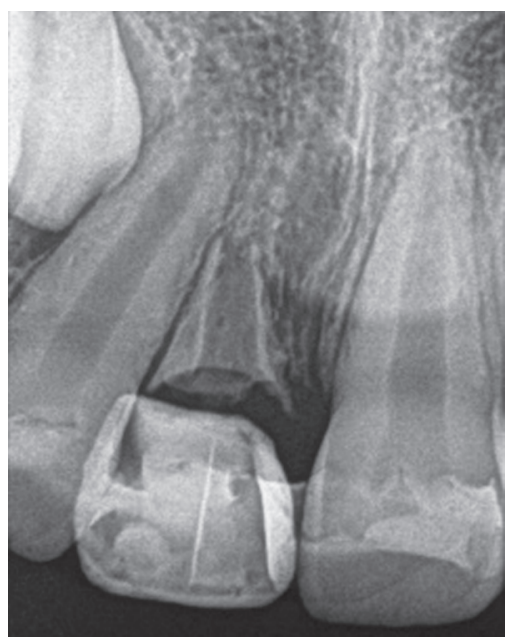

Fig. 7: Natural tooth pontic 11, stabilized with ribbond

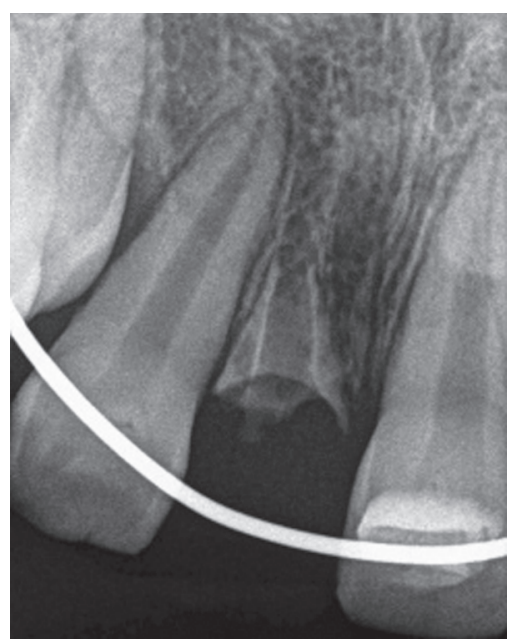

Fig. 9: Radiographic examination after 4 years showing arrested root resorption and formation of bone at previous resorptive sites

In growing individuals, the alveolar bone width and the alveolar ridge vertical bone growth are preserved with the decoronation procedure. During root resorption, the root that has been decoronated acts as a matrix for new bone formation. When the adjacent teeth erupt, there is the formation of new periosteum over the decoronated root which allows the growth of the vertical alveolar bone. Marginal bone apposition is evident with the continuous eruption of these teeth. There is a direct connection between the erupting teeth and the periosteum which covers the alveolar socket and is indirectly linked via the alveolar gingival fibers. Bone apposition is seen on the top of the alveolar crest due to the traction force generated by both these structures. ${ }^{12}$ Two cases have been reported by Malmgren et al. with the evidence of preservation of ridge width. ${ }^{13}$ According to Filippi et al. following decoronation, a slight decrease in ridge with is seen. However, after 9 months of follow-up, it remained constant. ${ }^{14}$ Lin et al. reported that following decoronation the effectiveness of alveolar ridge width preservation is not $100 \% .^{15}$

The option for esthetic rehabilitation of the decoronated tooth for children at mixed dentition is (1) natural tooth pontic, (2) use of a removable acrylic partial denture or, (3) lingual archwire with bands on permanent first molar and a decoronated or acrylic crown fixed to the archwire. ${ }^{16}$ 
In the present case, despite poor prognosis pulp revascularization has been attempted by reimplanting the tooth. But, it was not achieved and the tooth became ankylosed and had replacement root resorption. Along with it, the tooth was impending to the lower lip and appeared unesthetic. It was suggested by Malmgren to perform decoronation within 2 years when in the early mixed dentition ankylosis is diagnosed to avoid the risk of infraposition. For the primary stability of the implant, alveolar ridge height can be preserved successfully with the procedure of decoronation. ${ }^{17}$ In the current case, decoronation was planned with taking care of the age of the patient and the necessity of ridge preservation for future implant placement. The patient was followed for 4 years, radiographically suggested the evidence of arrested root resorption with the formation of bone at previous resorptive sites, which resulted in the preservation of alveolar ridge.

There are very few cases reports about monitoring decoronation as a treatment option for the ankylosed reimplanted tooth. In this case, the treatment option was successfully utilized in the management of malfunctioning mobile infraoccluded tooth for future implant placement despite providing temporary prosthesis at a young age.

Decoronation is a less traumatic and safe technique compared to complete extraction for the preservation of the height and width of the alveolar bone. It is an effective means for the preservation of alveolar ridge in teeth affected by replacement resorption. Decoronated crown as a temporary adhesive pontic treatment is also well accepted by the patient.

\section{References}

1. Andreasen JO, Ravn JJ. Epidemiology of traumatic dental injuries to primary and permanent teeth in a Danish population sample. Int J Oral Surg 1972;1(15):235-239. DOI: 10.1016/S0300-9785(72)80042-5.

2. Glendor U, Halling A, Andersson L, et al. Incidence of traumatic tooth injuries in children and adolescents in the county of Vastmanland, Sweden. Swed Dent J 1996;20(1-2):15-28.

3. Sala M, Mensoza-Mendoza A, Yañez-Vico R. Decoronation: an alternative treatment for replacement root resorption. Case Rep Dent 2017;2017:2826948. DOI: 10.1155/2017/2826948.

4. Andreasen JO, Andreasen FM, Andersson L, ed. Textbook and Color Atlas of Traumatic Injuries to the Teeth. 4th ed., Copenhagen: Munksgaard; 2007. pp. 850-852.
5. Andersson L, Blomlöf L, Lindskog S, et al. Tooth ankylosis. Clinical, radiographic and histological assessments. Int J Oral Surg 1984;13(5):423-431. DOI: 10.1016/S0300-9785(84)80069-1.

6. Malmgren B. Decoronation: how, why, and when? J Calif Dent Assoc 2000;28(11):846-854.

7. Malmgren $B$, Cvek $M$, Lundberg $M$, et al. Surgical treatment of ankylosed and infrapositioned reimplanted incisors in adolescents. Scand J Dent Res 1984;92(5):391-399. DOI: 10.1111/j.1600-0722.1984. tb00907.x.

8. Malmgren B. Ridge preservation/decoronation. J Endod 2013;39(Suppl):S67-S72. DOI: 10.1016/j.joen.2012.11.056.

9. Andreasen FM, Vestergaard Pedersen B. Prognosis of luxated permanent teeth - the development of pulp necrosis. Endod Dent Traumatol 1985;1(6):207-220. DOI: 10.1111/j.1600-9657.1985. tb00583.x.

10. Hammarstrom L, Lindskog S. General morphological aspects of resorption of teeth and alveolar bone. Int Endod J 1985;18(2):93-108. DOI: 10.1111/j.1365-2591.1985.tb00426.x.

11. Malmgren $\mathrm{O}$, Malmgren $\mathrm{B}$. Orthodontic management of the traumatized dentition. In: Andreasen FM, Andreasen JO, Andersson L, ed. Textbook and Color Atlas of Traumatic Injuries to the Teeth. Copenhagen: Munksgaard; 2007. pp. 669-715.

12. Malmgren B, Tsilingaridis G, Malmgren O. Long-term follow up of 103 ankylosed permanent incisors surgically treated with decoronation-a retrospective cohort study. Dent Traumatol 2015;31(3):184-189. DOI: 10.1111/edt.12166.

13. Malmgren B, Malmgren $O$, Andreasen JO. Alveolar bone development after decoronation of ankylosed teeth. Endod Top 2006;14(1):35-40. DOI: 10.1111/j.1601-1546.2008.00225.x.

14. Filippi A, Pohl Y, von Arx T. Decoronation of an ankylosed tooth for preservation of alveolar bone prior to implant placement. Dent Traumatol 2001;17(2):93-95. DOI: 10.1034/j.16009657.2001.017002093.x.

15. Lin S, Schwarz-Arad D, Ashkenazi M. Alveolar bone width preservation after decoronation of ankylosed anterior incisors. J Endod 2013;39(12):1542-1544. DOI: 10.1016/j.joen.2013.08.003.

16. Diaz JA, Sandoval HP, Pineda Pl, et al. Conservative treatment of an ankylosed tooth after delayed replantation: a case report. Dent Traumatol 2007;23(5):313-317. DOI: 10.1111/j.1600-9657.2006. 00463.x.

17. Mohadeb JV, Somar M, He H. Effectiveness of decoronation technique in the treatment of ankylosis: a systematic review. Dent Traumatol 2016;32(4):255-263. DOI: 10.1111/edt.12247. 